\title{
CORPO E SEXUALIDADE: dos dispositivos disciplinares à estética da existência ${ }^{1}$
}

\section{CUERPO Y SEXUALIDAD: de los dispositivos disciplinares a la estética da existencia}

\author{
Francisco Danilo dos Santos Oliveira ${ }^{2}$
}

Francisco Rômulo Alves Diniz ${ }^{3}$

\begin{abstract}
Resumo: Propõe-se com esse trabalho aprofundar os estudos sobre as concepções filosóficas de Michel Foucault acerca da sexualidade e o corpo nos seus aspectos fundamentais. Os estudos foucaultianos revelam como essa sexualidade foi usada para manter relações de poder e de subjugação dos indivíduos e seus corpos. Foucault, nos volumes de História da sexualidade, aborda essa realidade decontrole e manutenção do poder apresentando os dispositivos da sexualidade, o seu desenvolvimento e aplicações para uma relação de controle dos indivíduos, mas, também formas de superação desse esquema. Para Foucault, o discurso, um dos principais artifícios utilizado para o controle dos indivíduos, não deve mais subjugar os corpos, mas o corpo deve produzir seu discurso a partir de uma performance própria, reveladora de dignidade e grandeza, é aquilo que Foucault nomeia de estética da existência e posteriormente desenvolve como cuidado de si.
\end{abstract}

Palavras-chave: Corpo. Sexualidade. Foucault.

Resumen: Propongo este trabajo para profundizar los estudios sobre las concepciones filosóficas de Michel Foucault sobre la sexualidad y el cuerpo y sus aspectos fundamentales. Los estudios de Foucault revelaron cómo se utilizó esta sexualidad para mantener las relaciones de poder y subyugación entre dos individuos y sus cuerpos. Foucault, en los volúmenes de Historia de la sexualidad, aborda esta realidad de control y mantenimiento del poder introducido los dispositivos de la sexualidad, es decir, su desarrollo y aplicaciones para una relación de control dos individuos, además, también formas de superar este esquema. Para Foucault, el discurso, los principales artefactos utilizados para controlar los individuos ya no deberían servir para subyugar los cuerpos, sino que cualquiera de los cuerpos debe producir su discurso a partir de una actuación adecuada, revelando dignidad y grandeza, etc. que Foucault no hizo la estética da existencia y luego se despliega como autocuidado.

\footnotetext{
${ }^{1}$ Esta pesquisa é desenvolvida no âmbito do Grupo de Estudo em Política, Educação é Ética - GEPEDE - UVA - CNPq e do Laboratório de Estudos da Política - LEPOL - UVA, ambos sob a coord. Do Prof. Dr. Ricardo George de Araújo Silva. Esta temática corresponde ao nosso mestrado acadêmico em filosofia, cursado na Universidade Estadual Vale do Acaraú - UVA, Sobral-CE.

2 Graduado em Tecnologia, em Eletromecânica pela FATEC- Faculdade de Tecnologia do Ceará, graduado em Filosofi a e especialista em Juventude no Mundo Contemporâneo pela Faculdade Jesuíta de Filosofia e Teologia - FAJE, e atualmente é mestrando em Filosofia pela Universidade Vale do Acaraú - UVA. E-mail do autor: danilosantossax@yahoo.com.br
}

${ }^{3}$ Mestre em Filosofia pela Universidade Federal da Paraíba (2000) e doutorado em Filosofia (UFPB-UFPEUFRN) (2012). Professor efetivo do Curso de Filosofia (Bacharelado e Licenciatura) e do Mestrado Acadêmico em Filosofia da Universidade Estadual Vale do Acaraú. E-mail: romulodiniz40@gmail.com . 
Palabras-clave: Cuerpo. Sexualidad. Foucault.

\section{Introdução}

O corpo é um dos grandes temas do pensamento filosófico, sempre esteve presente nas discussões, da polis grega aos dias atuais, sobre a divisão da alma aos papéis sociais de gênero. $\mathrm{O}$ termo, desta forma, ganha relevância para a compreensão das relações humanas face à organização política e social provocando disputas e embates por sua utilização, nesta área do conhecimento. Michel Foucault, filosofo francês de grande importância, em seus estudos dedicou-se a compreender os aspectos fundamentais que envolveram as diversas concepções de corpo, com apropriações e rupturas, na esteira da filosofia política.

Foi no bojo da filosofia política do século XVI, pelo avanço no conhecimento das ciências naturais, principalmente a medicina e sua prática de dissecação de corpos e a compreensão de sua anatomia, que o corpo foi tomado como metáfora do estado monárquico. No início do século XVII com o "aparecimento de técnicas de poder, que eram essencialmente centradas no corpo individual" (FOUCAULT, 2005, p.288), os dispositivos disciplinares, vemos "aparecer uma anátomo-política do corpo humano" (FOUCAULT, 2005, p.289), posteriormente, tornando-se objeto de cuidado e atenção dos governos por meio da normatização da vida, tendo seu auge com o que Foucault denomina de uma "biopolítica da espécie humana" (FOUCAULT, 2005, p.289).

Neste contexto, opera-se uma passagem nas sociedades de "uma simbólica do sangue para uma analítica da sexualidade" (FOUCAULT, 2014a, p. 145), o sexo torna-se, então, um dos aspectos mais relevantes para elucidação das questões envolvendo o conceito foucaultiano de corpo. O sexo converte-se no elo entre os dispositivos disciplinares, corpo-indivíduo, e a normatização, corpo-espécie.

\section{Corpo, sexo e as políticas de gerenciamento da vida}

Hobbes, pensador inglês do século XVI, é um dos primeiros a trazer para a reflexão o termo "corpo" na perspectiva da teoria política. O seu livro mais célebre, Leviatã, trata sobre o governo absolutista e a arte de governar. Nesse primeiro momento, nosso interesse concentra-se na concepção de corpo expressada nessa obra, principalmente pela imagem que ilustra a capa da primeira edição. $\mathrm{Na}$ referida capa pode-se constatar a importância do corpo para sua percepção acerca da vida e organização da cidade.

A capa traz a figura de um rei que teria seu corpo formado pela junção de corpos, representando o 'corpo da população' onde residiria a autoridade do rei, em uma das mãos segura uma espada simbolizando o poder sobre o exército e a segurança, na outra mão um cetro simulando 
o poder soberano do monarca. Essa imagem do rei se eleva acima da cidade representando a proteção do rei aos seus súditos e a manutenção da cidade.

Essa representação é importante para a compreensão das diversas expressões que o governo absolutista deve enfrentar para permanecer no comando e manter a cidade equilibrada, porém essa imagem é invocada para observar, justamente, o aspecto da representação do 'corpo da população’, pois o poder absoluto havia sido estabelecido pelo próprio povo, o corpo-indivíduo de cada súdito morador do reino, era em parte o sustentador do rei. Por sua vez, os súditos "estão premidos pelo perigo ou pela necessidade. Eles os fazem [contrato social], por conseguinte, para proteger à vida" (FOUCAULT, 2005, p.287- acréscimo nosso), da insegurança e da morte violenta, com isso o soberano dispõe da vida de seus súditos. O súdito é, assim,

\begin{abstract}
do ponto de vista da vida e a da morte, neutro, e é simplesmente por causa do soberano que o súdito tem direito de estar vivo ou tem o direito, eventualmente, de estar morto. Em todo caso, a vida e a morte dos súditos só se tornam direitos pelo efeito da vontade soberana. [...] O direito de vida e de morte só se exerce de uma forma desequilibrada, e sempre do lado da morte. (FOUCAULT, 2005, p.286).
\end{abstract}

Foucault vai recuperar essa imagem da obra Leviatã para falar como é necessário o estudo do corpo e sua relação com o poder. Ao se referir ao Leviatã, Foucault comenta:

O Leviatã não é outra coisa senão a coagulação de um certo número de individualidades separadas, unidas por um conjunto de elementos constitutivos do Estado; mas no coração do estado ou melhor em sua cabeça, existe algo que o constitui como tal e este algo é a soberania, que Hobbes diz ser precisamente a alma do Leviatã. [..., mas também] creio que seria preciso procurar estudar os corpos periféricos e múltiplos, os corpos constituídos como sujeitos pelos efeitos de poder. (FOUCAULT, 1979, p.102 acréscimo nosso)

O pensamento hobbesiano influência na formulação da concepção de corpo em Foucault. O pensador francês analisa a importância da concepção de corpo em relação ao poder em Hobbes e ao mesmo tempo busca compreender os diversos corpos que não estão nessa estrutura do poder soberano, ou seja, direciona-se a entender os corpos na perspectiva daqueles que estão nas periferias e que são muitos e múltiplos. Por isso, para Foucault,

\footnotetext{
é preciso desvencilhar-se do modelo do leviatã, desse modelo de homem artificial, a um só tempo autônomo, fabricado e unitário igualmente, que envolveria todos os indivíduos reais, e cujo o corpo seria os cidadãos, mas cuja a alma seria a soberania. É preciso estudar o poder fora do modelo do Leviatã, fora do campo delimitado pela soberania jurídica e pela instituição do Estado; tratasse de analisá-lo a partir da técnicas e táticas de dominação. (FOUCAULT, 2005, p.30).
}

O autor busca entender a mecânica do funcionamento do corpo e como as engrenagens, as práticas e instrumentos podem levar o corpo a tornar-se útil e funcional. As tecnologias do 
poder $^{4}$ vão atuar para que esse corpo possa se adequar a essas novas perspectivas, pois o corpo tem uma mutabilidade, que "modela-se, treina-se, que obedece, responde, torna-se hábil ou cujas forças se manipulam" (FOUCAULT, 1979, p. 134). Assim, as "técnicas de racionalização e de economia estrita de um poder que devia se exercer, da maneira menos onerosa possível, mediante todo um sistema de vigilância, de hierarquias, de inspeções, de escriturações, de relatórios: toda essa tecnologia disciplinar" (FOUCAULT, 2005, p.288), ou seja, por meio de uma docilização dos corpos.

A docilização, nessa perspectiva, é um dos principais conceitos atribuídos ao corpo, pois é através de uma "manipulação calculada de seus elementos e gestos, de seus comportamentos [...] que o corpo humano entra numa máquina do poder que o esquadrinha, o desativa e o recompõe” (FOUCAULT, 1979, p. 135- acréscimo nosso). Esses dispositivos "centrados no corpo, produz efeitos individualizantes" (FOUCAULT, 2005, p.297) que são representados, principalmente, pela disciplina e, especificamente, os dispositivos disciplinares da sexualidade, como modos para alcançar um tipo desejado de corpo. A sexualidade,

enquanto comportamento exatamente corporal, depende do controle disciplinar, individualizante, em forma de vigilância permanente (e os famosos controles, por exemplo, da masturbação que foram exercidos sobre as crianças desde o fim do século XVIII até o século XX, e isto no meio familiar, no meio escolar, etc., representam exatamente esse lado do controle disciplinar da sexualidade). (FOUCAULT, 2005, p.300)

Para essa percepção há números significativos de publicações para falar do perigo do toque nas genitálias, ou seja, uma série de recomendações acerca da masturbação, principalmente, aos pais para o cuidado dos filhos. Foucault vai dizer, sobre sua pesquisa, que o tema da masturbação nunca encontrou nenhum relato que trata da masturbação como sendo algo do tipo normal ou anormal. Então, o discurso da masturbação é compreendido em sua especificidade de controle sobre os corpos da criança, na perspectiva da sexualidade e da saúde do adulto no futuro.

Há um esforço contínuo para que a masturbação seja controlada, e levantada a hipótese que a masturbação está no fato do "desenvolvimento capitalista, o corpo, que era então, diz Van Ussel, um 'órgão de prazer', se torna e deve se tornar um 'instrumento de desempenho'

\footnotetext{
${ }^{4}$ As tecnologias do poder são diversos técnicas que fazem produzir indivíduos dóceis e economicamente rentáveis e, por isso, são as bases do dispositivo disciplinar. Se dão, por exemplo, pela "distribuição dos corpos em um espaço quadriculado e articulado, definido em relação a uma determinada função e ordenado em termos classificatórios: cada preso em sua cela, cada doente em sua cama, cada aluno em sua carteira, cada empregado em seu escritório ou junto a sua máquina. Em segundo lugar, o controle da atividade mediante o horário e o ajuste dos comportamentos e gestos à temporalidade de um processo. Em terceiro lugar, a organização genética do tempo, mediante a segmentação da temporalidade de um processo e a serialização de atividade repetitivas e sucessivas. E, finalmente, a composição das séries temporais mediante uma estrita linha de mando. Cada técnica define as características próprias da individualidade disciplinar: celular, genética, orgânica e combinatória." (CASTRO, 2014, P. 93)
}

Cadernos Cajuína, V. 5, N. 2, 2020, p. 36-47. 
desempenho esse necessário às próprias exigências da produção” (FOUCAULT, 1979, p.205). Mesmo sendo uma tese muito interessante levantada por Val Ussel, Foucault vai esclarecer que não é suficiente para explicar a complexidade da sexualidade ou se há uma relação entre a masturbação e a produção fabril, mas, no entanto, fornece elementos importantes para compreender as sutilezas da problemática que envolve a disciplina e o controle de corpos.

A disciplina procura por meio desse "corpo dócil que pode ser submetido, que pode ser utilizado, ser transformado e aperfeiçoado" (FOUCAULT, 1979, p. 134), um enquadramento que o torne útil para ordenamento social produtivo e eficaz. Por isso, diversas técnicas são aplicadas, como os "regulamentos militares, escolares, e por processos empíricos e refletidos para controlar ou corrigir as operações do corpo" (FOUCAULT, 1979, p. 134). A disciplina preocupa-se com os pequenos detalhes, como o "esmiuçar das inspeções, controle das mínimas parcelas da vida e do corpo [...], uma racionalidade econômica ou técnica a esse cálculo místico do ínfimo e do infinito" (FOUCAULT, 1979, p. 138), a pretensão é a "manipulação do corpo como foco de forças que é preciso tornar úteis e dóceis ao mesmo tempo" (FOUCAULT, 2005, p.297).

Foucault, em sua análise, observa também, uma outra forma de poder que não a disciplinar, mais abrangente e completa, não para negar ou superar a anterior, uma nova técnica que não está mais centrado em um corpo específico, mas no corpo geral da população. "Essa nova técnica não suprime a técnica disciplinar simplesmente porque é de outro nível, está noutra escala, tem outra superfície de suporte e é auxiliada por instrumentos totalmente diferente" (FOUCAULT, 2005, p.289), é o que vai chamar de biopolitica.

A biopolítica está "centrado no corpo-espécie, no corpo transpassado pela mecânica do ser vivo e como suporte dos processos biológicos" (FOUCAULT, 2014a, p. 130) tendo em vista que essa

nova tecnologia que se instala se dirige à multiplicidade dos homens, não na medida em que eles resumem em corpos, mas na medida em que ela forma, ao contrário, uma massa global, afetada por processos de conjunto que são próprios da vida, que são processos como o nascimento, a morte, a produção, a doença, etc.(FOUCAULT, 2005, p.289).

$\mathrm{Na}$ modernidade, “o homem é um animal, em cuja política, sua vida de ser vivo estar em questão" (FOUCAULT, 2014a, p. 134), diferentemente daquilo que Aristóteles havia definido sobre o homem como zoon politikon, um "animal vivo [...] capaz de existência política" (FOUCAULT, 2014a, p. 134), ou seja, o direito do soberano sofre uma inversão, passando do "fazer morrer e deixar viver" (FOUCAULT, 2005, p.287) ao "fazer viver e deixar morrer" (FOUCAULT, 2005, p.287) da biopolítica. O "velho direito de causar a morte ou deixar viver foi 
substituído por um poder de causar a vida ou devolver à morte" (FOUCAULT, 2014a, p. 130) em uma perspectiva de ordenamento da vida e das caraterísticas que a potencialize ou que a debilite.

Por conseguinte, a vida do corpo-espécie passa a ser a principal preocupação dos governos em suas dimensões biológicas, como: “a proliferação, os nascimentos e a mortalidade, o nível de saúde, a duração da vida, longevidade, com todas as condições que podem fazê-lo variar; tais processos são assumidos mediante toda uma série de intervenções e controle reguladores" (FOUCAULT, 2014a, p. 130). Há também aqueles acontecimentos aleatórios que são "fenômenos dos quais uns são universais e outros acidentais, mas que, de uma parte, nunca são inteiramente compreensivos" (FOUCAULT, 2005, p.291).

Os acontecimentos aleatórios são fenômenos que "aparecem com seus efeitos econômicos e políticos que só se tornam pertinentes no nível da massa" (FOUCAULT, 2005, p.293), por isso objeto de preocupação de governos e seu intuito de controle da vida da população. Esses acontecimentos aleatórios, "ocorre numa população considerada em sua duração" (FOUCAULT, 2005, p.293), são principalmente eventos que se dão não sobre o corpo-indivíduo, mas sobre o corpo-espécie e que "introduz sorrateiramente na vida, a corrói perpetuamente, a diminui e a enfraquece" (FOUCAULT, 2005, p.291). Nos mecanismos implantados pela biopolítica,

\begin{abstract}
vai se tratar sobretudo, é claro, de previsões, de estimativas estatísticas, de medições globais; vai se tratar, igualmente, não de modificações tal fenômeno especial, não tanto tal indivíduo, na medida em que é indivíduo, mas, essencialmente, de intervir no nível daquilo que são as determinações desses fenômenos gerais, desses fenômenos no que eles têm de globais. (FOUCAULT, 2005, p.293)
\end{abstract}

Nesse contexto, Foucault reconhece no sexo um papel de muita importância, tendo em vista a abrangência que o sexo tem tanto relacionado aos aspectos da disciplina dos corpos, como da normatização da vida. O pensador recorre ao seu método genealógico-arqueológico para analisar a dinâmica peculiar que o sexo assume na modernidade "compreendendo a importância assumida pelo sexo como foco de disputa política" (FOUCAULT, 2014a, p. 136). A relevância do sexo, conclui, dá-se por localiza-se em um lugar fronteiriço entre esses dois polos, pois o "sexo é acesso, ao mesmo tempo, à vida do corpo e a vida da espécie" (FOUCAULT, 2005, p.300).

É que ele se encontra na articulação entre a tecnologia política da vida. De um lado, faz parte das disciplinas do corpo: adestramento, intensificação e distribuição das forças, ajustamento e economia das energias. Do outro, o sexo pertence a regulação das populações, por todos os efeitos globais que induz. (FOUCAULT, 2014a, p. 136)

Foucault usa o exemplo da cidade operária para fundamentar esses "dois conjuntos de mecanismos, um disciplinar, outro regulamentador" (FOUCAULT, 2005, p.299) que não estão no mesmo nível, mas se articulam um ao outro. Os mecanismos disciplinares sobre o corpo- 
indivíduo se dão pelo "recorte da cidade, pela localização das famílias (cada um em sua casa) e dos indivíduos (cada um no seu cômodo)" (FOUCAULT, 2005, p.300) e os mecanismos regulamentadores que são

vinculados ao hábitat, à localização do hábitat. Sistema de seguro-saúde ou de segurovelhice; regras de higiene que garanta a longevidade ótima da população; pressões que a própria organização da cidade exerce sobre a sexualidade, portanto sobre a procriação; as pressões que se exerce sobre a higiene das famílias; os cuidados dispensados às crianças; a escolaridade, etc. (FOUCAULT, 2005, p.300)

O sexo, na percepção foucaultiana, é a principal maneira de gerenciamento da vida das pessoas, mas não no sentido de uma proibição profunda aos atos sexuais, mas por “[...] meio de um discurso úteis e públicos” (FOUCAULT, 2014a, p.27), que ajudassem a consolidar o poder sobre os corpos. Neste momento, a sexualidade toma contornos importantes, "longe de ser reprimida na sociedade contemporânea está ao contrário, sendo permanentemente sustentada" (FOUCAULT, 2014a, p.139), assim, com o crescimento das cidades, a política que visa levantamentos de dados da população com relação à sexualidade passa a ser necessária.

Dar início, desta forma, as análises sobre "[...] a taxa de natalidade, a idade do casamento, os nascimentos legítimos e ilegítimos, a precocidade e a frequência das relações sexuais, a maneira de torná-las fecundas ou estéreis" (FOUCAULT, 2014a, p.27.). “De um modo geral, na junção entre o ‘corpo' e a 'população' o sexo tornou-se o alvo central de um poder que se organiza em torno da gestão da vida, mais do que da ameaça de morte" (FOUCAULT, 2014a, p.138). Tais recursos estão, hoje, na base de qualquer ação governamental.

\section{Os dispositivos disciplinares e a estética da existência ${ }^{5}$}

Foucault debruça-se sobre determinadas classes de pessoas a serem submetidas mais fortemente aos dispositivos disciplinares de manutenção e controle social, ou seja, "corpos específicos escolhidos para o 'sujeitamento', dadas suas condições de subalternação e exclusão, são elas: as crianças, as mulheres, os pervertidos - aqueles que tinham práticas não condizentes com o estabelecido como, por exemplo, os homossexuais" (OLIVEIRA, 2020, p. 93). Esses tipos específico de pessoas são as que mais sofreram nessa perspectiva de implantação de um sistema heteronormativo.

Há diversas forças de desarticulação do próprio sistema que estão presentes nesses corpos que foram (ou são) os mais suscetíveis a sofrer punições e restrições. "A utilização dos sistemas jurídicos, médicos e escolares, nas formas de lei, de medicalizações e de pedagogias são

5 Este tópico foi desenvolvido de forma mais sistemática no artigo: Corpo, sexualidade e juventude:Provocações de uma ética foucaultiana para centros socioeducativos, publicado na revista Annales Faje, em novembro de 2020. 
instrumentos na manutenção e reafirmação do regime estabelecido que deve ser mantido para que a obediência e a ordem permaneçam estáveis" (OLIVEIRA, 2020, p. 93). Assim, essas três grandes áreas do conhecimento formuladas ao longo de muitos anos eram utilizadas, respectivamente, para que fossem "controlados os pervertidos, com suas práticas perigosas; a mulher histérica, com sua patologia intrínseca; e a criança com a educação do toque e culpabilização do desejo" (OLIVEIRA, 2020, p. 93).

A pastoral cristã, principalmente a igreja católica, utilizava a tecnologia da confissão como uma das "grandes práticas de exercer o poder sobre os indivíduos que não tinham como fugir da confissão forçada de si” (OLIVEIRA, 2020, p. 93). Esse poder se exerce, como “[...] presenças constantes, atentas e também curiosas; ela implica proximidades; procede mediante exames e observações insistentes; requer um intercâmbio de discursos através de perguntas que extorquem confissão e de confidências que superam a inquisição". (FOUCAULT, 2014a, p.49)

A diminuição do poder controlador da Igreja em relação a sua hegemonia na idade média e o crescimento da burguesia, traz novos contornos com relação à sexualidade e ao corpo. "Essa postura nova é assumida pela medicina e sua maneira clínica e objetiva de tratar a pessoa, pela qual a padronização dos corpos ganha contornos de uma higienização que traga saúde e, assim, passa a dominar o campo da busca e da regulação e extinção de corpos que não se enquadram nos padrões médicos vigentes" (OLIVEIRA, 2020, p. 94).

O exame médico, a investigação psiquiátrica, o relatório pedagógico e os controles familiares podem, muito bem, ter como objetivo global e aparente dizer não a todas as sexualidades errantes ou improdutivas, mas, na realidade, funcionam como mecanismos de dupla incitação: prazer e poder. (FOUCAULT, 2014a, p.50)

Foucault ao indagar sobre esta trama profunda do desejo de saber sobre o sexo e suas formas de ligação com o prazer. Há um jogo existente entre dois lados, um entrelaçamento em que “[...] o prazer se mistura ao involuntário e o consentimento à inquisição" (FOUCAULT, 2014a, p.49), como se passassem naturalmente de um para o outro: "saber do prazer, prazer de saber o prazer, prazer-saber" (FOUCAULT, 2014a, p.85).

Para o Foucault há uma estreita ligação entre o desejo de conhecimento e o sexo, nessa relação há um prazer embutido, que ao pesquisar a história da sexualidade se depara com "distintos momentos em que isso se torna forte, seja no cristianismo feudal declinante, seja na burguesia crescente onde o tema exercia grande fascínio sobre os indivíduos". (OLIVEIRA, 2020, p. 94) Por isso, os dispositivos disciplinares ressaltados por Foucault com relação aos corpos e sua sexualidade não se dão de forma ingênuos. Esses dispositivos funcionam como

[...] o conjunto dos efeitos produzidos nos corpos, nos comportamentos, nas relações sociais, por um certo dispositivo pertencente a uma tecnologia política complexa [...]. 
Deve-se reconhecer que esse dispositivo não funciona simetricamente lá e cá, e não produz, portanto, os mesmos efeitos.” (FOUCAULT, 2014a, p.139)

Ao trabalhar os dispositivos disciplinares da sexualidade, Foucault quer demostrar como eles foram "desenvolvidos e como passaram de pequenas experiências em monastérios a todo o povo, de corpos individuais ao corpo geral das populações para que o regime de poder pudesse ser assegurado e fortalecido, por uma questão de domínio em suas diversas formas de manifestação" (OLIVEIRA, 2020, p. 94). Lembramos que o poder, nessa forma de relação com a sexualidade e com os corpos, como expressão que dita as leis, é sempre situado de uma maneira negativa, seja de rejeição, seja de exclusão.

Foucault em seu percurso investigativo "aponta um caminho de superação desses engendramentos em que o poder, a sexualidade, o saber e os corpos se encontravam. O caminho do cuidado de si e de uma ética no uso dos prazeres, ou seja, um modo adequado de vivenciar a sexualidade e a corporeidade, rompendo com os dispositivos que os subjugam" (OLIVEIRA, 2020, p. 94). O autor propõe aqui uma ética diferenciada da proposta pela filosofia clássica, denominada de ética da carne.

Foucault propõe "a temperança como um caminho de reconhecimento de si e vivência da afrodisia" (OLIVEIRA, 2020, p. 95). A aphrodisia era maneira, como os gregos entendiam, a sexualidade e sua prática. Este termo correspondia ao “[...] verbo aphodisiazein, [uma] referência à atividade sexual em geral" (FOUCAULT, 2014b, p.56).

A vivência de uma ética em relação a sexualidade não direciona para uma das dimensões próprias dela nem se restringiam ao próprio ato, nem ao desejo, nem ao prazer, mas estava fixa “[...] sobretudo na dinâmica que une os três de maneira circular (o desejo que leva ao ato, o ato que é ligado ao prazer e o prazer que suscita o desejo)" (FOUCAULT, 2014b, p.54).

Foucault refletindo sobre essa relação entre "atos, desejos e prazeres que poderiam levar a uma vida intemperante e desordenada, uma vida sem a vivência de uma ética, chega à conclusão que o problema ético estará na intensidade da relação desses três aspectos” (OLIVEIRA, 2020, p. 95)., pois, para ele, essa “[...] relação dinâmica [dos aspectos] que constitui o que se poderia chamar o grão da experiência ética da aphrodisia" (FOUCAULT, 2014b, p.54), onde o problema ético encontra-se na frequência dos atos e na intensidade de tais práticas em uma divisão entre extremos, entre o “[...] menos e mais: moderação ou continência” (FOUCAULT, 2014b, p.54) e nunca sobre proibições.

Foucault, aludindo à prática sexual como algo natural e indispensável, não deixa de lembrar que mesmo ela é parte de um cuidado moral. É imprescindível que se tenha algum tipo 
de demarcação que “[...] permita fixar até que ponto, e em que medida, é conveniente praticá-la". (FOUCAULT, 2014b, p.60) tendo em vista toda a vivacidade natural que o prazer proporciona. No texto já enfatizamos a relação da vontade de saber sobre os corpos e a sexualidade. No entanto, Foucault, "refletindo Aristóteles, volta a falar sobre a importância do conhecimento para que se mantenha a temperança na relação com a sexualidade, não mais na busca de domínio do outro" (OLIVEIRA, 2020, p. 94), mas de conhecimento de si e na afirmação do homem temperante e sua relação com a verdade na vivência moral da sexualidade. Segundo o autor,

[...] qualquer que seja o modo de saber suposto naqueles que agem a despeito dos princípios que conhecem, existe um ponto que não é contestado: é que não se pode praticar a temperança sem uma forma de saber que constitui pelo menos uma de suas condições essenciais. Não se pode constituir como sujeito moral no uso dos prazeres sem constituir-se ao mesmo tempo como sujeito do conhecimento. (FOUCAULT, 2014b, p.103).

Para Foucault, a relação do conhecimento e a verdade é uma condição "estrutural, instrumental e ontológica da instauração do indivíduo como sujeito temperante e levando uma vida de temperança" (FOUCAULT, 2014b, p.107). Contudo, essa relação com a verdade não é condição "epistemológica para que o indivíduo se reconheça na sua singularidade de sujeito desejante" (FOUCAULT, 2014b, p.107), nem o conduziria a uma hermenêutica do sujeito.

Entretanto, essa busca pela verdade e pela instauração do sujeito temperante abre para aquilo que Foucault vai chamar de uma estética da existência que, segundo ele, podemos denominar como

[...] uma maneira de viver cujo valor moral não está em sua conformidade a um código de comportamento nem em um trabalho de purificação, mas depende de certas formas, ou melhor, certos princípios formais gerais no uso dos prazeres, na distribuição que deles se faz, nos limites que se deve observar, na hierarquia que se respeita. (FOUCAULT, 2014b, p.107).

Essa sugestão que propõe Foucault se ergue em contraponto aos dispositivos disciplinares, pois a proposta de uma "estética da existência parte, principalmente, de uma liberdade do sujeito que não se deixa mais submeter-se aos diversos discursos sobre seu corpo e sua sexualidade, que sejam determinantes ou restritivos de sua essência a fim de reafirmarem algum regime de poder" (OLIVEIRA, 2020, p. 94). Assim,

[...] nem os médicos, ao darem conselhos de regime, nem os moralistas, ao pedirem aos maridos que respeitem suas esposas, nem aqueles que dão conselhos sobre a boa conduta no amor pelos rapazes, dirão exatamente o que é preciso ou não fazer na ordem dos atos ou práticas sexuais. (FOUCAULT, 2014b, p.111)

\section{A sexualidade, corpo e a arte de viver}

Foucault, ao trabalhar os dispositivos disciplinares, quer mostrar como eles foram desenvolvidos e passaram de pequenas experiências em monastérios a todo o povo, de corpos 
individuais ao corpo geral das populações para que o regime de poder, por meio da bioplítica, pudesse ser assegurado e fortalecido, por uma questão de domínio em suas diversas formas de manifestação. "De um polo a outro dessa tecnologia do sexo, escalona-se toda uma série de táticas diversas que combina, em proporções variadas; o objetivo da disciplina do corpo e a regulamentações das populações" (FOUCAULT, 2014a, p. 137). O poder, nessa relação com a sexualidade e com os corpos, como expressão que dita às leis, é sempre estabelecido em uma relação negativa, seja de rejeição, seja de exclusão.

Por isso, os dispositivos disciplinares ressaltados por Foucault com relação aos corpos e sua sexualidade não se dão de forma ingênuas. Esses dispositivos funcionam como um "conjunto dos efeitos produzidos nos corpos, nos comportamentos, e relações sociais, a partir de um certo dispositivo pertencente à uma tecnologia política complexa [...]. Deve-se reconhecer que esse dispositivo não funciona simetricamente lá e cá, e não produz, portanto, os mesmos efeitos.” (FOUCAULT, 2014a, p.139)

No entanto, Foucault aponta em seus últimos escritos um caminho de superação desses engendramentos em que o poder, a sexualidade, o saber e os corpos se encontravam. O caminho do cuidado de si e de uma ética no uso dos prazeres, ou seja, um modo adequado de vivenciar a sexualidade e a corporeidade, rompendo com os dispositivos que os subjugam. O autor propõe uma ética, que é também uma posição política, diferenciada da proposta pela filosofia clássica. Conclui Foucault, sobre essa arte de viver que sempre engloba o indivíduo e suas relações. Ele diz que a "moral sexual exige, ainda e sempre, que o indivíduo se sujeite a uma certa arte de viver que define critérios estéticos e éticos da existência" (FOUCAULT, 2014c, p.87). Todavia, essa moral se refere cada vezmais a "princípios universais da natureza ou da razão, aos quais todos devem se curvar da mesma maneira, qualquer que seja o status”. (FOUCAULT, 2014c,p.87)

\section{Referências}

CASTRO, Edgardo. Introdução a Foucault. Belo Horizonte: Autêntica Editora, 2014.

COSTA, Jurandir Freire. O sujeito em Foucault: estética da existência ou experimento moral? Tempo Social; Rev. Sociologia. USP, S. Paulo, 7 (1-2): 121-138, outubro de 1995.

FOUCAULT, Michel. História da sexualidade: a vontade de saber. São Paulo: Paz e Terra, 2014.

FOUCAULT, Michel. História da sexualidade: o uso dos prazeres. São Paulo: Paz e Terra, 2014.

FOUCAULT, Michel. História da sexualidade: o cuidado de si. São Paulo: Paz e Terra, 2014. 
FOUCAULT, Michel. Cuidado de Si e Biopolítica: Saberes e práticas na constituição dos sujeitos contemporâneos. São Leopoldo: Instituto Humanitas Unisinos, v. 472, 14 set. 2015.

FOUCAULT, Michel. Corpo e Sexualidade: A contribuição de Michel de Foucault. São Leopoldo: Instituto Humanitas Unisinos, v. 335, 28 jun. 2010

FOUCAULT, Michel. Os anormais: Curso no collé de France (1974/1975). São Paulo : Editora WMF Martins Fontes, 2010

FOUCAULT, Michel. Microfisica do poder. 8a ed. Rio de Janeiro : Graael, 1979.

FOUCAULT, Michel. Segurança, território, população. São Paulo : Martins Fontes, 2005.

FOUCAULT, Michel. Vigiar e Punir: nascimento da prisão. 14a. Ed. Petrópolis : Vozes, 1996.

OLIVEIRA, Francisco. Corpo, sexualidade e juventude: provocações de uma ética foucaultiana para centros socioeducativos. Annales FAJE, Belo Horizonte, v. 5, n.1, p. 90-100, nov., 2020. 